\title{
A CONCEPÇÃO DOS EDUCADORES SOBRE A TEMÁTICA DE EDUCAÇÃO AMBIENTAL NA ESCOLA: DIFICULDADES E DESAFIOS
}

\section{THE CONCEPTION OF EDUCATORS ABOUT EDUCATION ENVIRONMENTAL IN SCHOOL: DIFFICULTIES AND CHALLENGES}

\section{Luana Biasibetti ${ }^{1}$, Mario Luiz Trevisan², Toshio Nishijima ${ }^{3}$, Paulo Edelvar Correa Peres ${ }^{4}$ UNIVERSIDADE FEDERAL DE SANTA MARIA - UFSM/RS}

\author{
${ }^{1}$ Especialista em Educação Ambiental pela Universidade Federal de Santa Maria - UFSM \\ ${ }^{2}$ Professor do Curso de Especialização em Educação Ambiental -UFSM
}

\begin{abstract}
Resumo
As questões ambientais vêm ganhando repercussão em nível mundial. Diversos são os fatores que vêm intensificando esses problemas, tais como a expansão demográfica, o uso descontrolado dos recursos naturais, a poluição e o desmatamento. $\mathrm{O}$ presente trabalho foi desenvolvido em uma Escola Estadual de Ensino Fundamental e Médio, em que foi utilizado como instrumento de coleta de dados um questionário semiestruturado sobre a temática de EA no contexto de sala de aula e a interdisciplinaridade no processo de ensino. A pesquisa justifica-se pela necessidade de mudanças de atitudes relacionadas com os aspectos ambientais, propondo o envolvimento dos professores da escola em atividades relacionadas à Educação Ambiental, problematizando suas concepções sobre as questões relacionadas à EA no contexto disciplinar. A entrevista buscou compreender a forma como os professores vêm trabalhando as questões relacionadas com a EA no contexto de sala de aula, verificando as dificuldades sentidas durante processo de sensibilização dos estudantes frente às questões ambientais. Contudo, percebe-se que a abordagem das questões ambientais no contexto de sala de aula deve ser considerada um grande desafio para os professores, uma vez que, por se tratar de assuntos amplos, diversificados e ricos em conceitos, eles sentem-se na sua maioria, despreparados para esta abordagem.
\end{abstract}

Palavras-chave: Educação Ambiental. Interdisciplinaridade. Contextualização do Ensino.

\begin{abstract}
Environmental issues are gaining repercussions worldwide. There are several factors that have intensified these problems, such as population growth, uncontrolled use of natural resources, pollution and deforestation. This work was developed in a State School of Elementary and Secondary Education, which used as a data collection instrument a semi-structured questionnaire on the theme of EE in the classroom context and interdisciplinarity in the teaching process. The research is justified by the need to change attitudes towards environmental issues, proposing the involvement of school teachers in activities related to environmental education, discussing his views on the EE-related issues in the disciplinary context. The interview aimed to understand how teachers have been working issues with EE in the classroom context, determining the difficulties experienced during the process of sensitization of the front students to environmental issues. However, it is clear that addressing environmental issues in the classroom context must be considered a great challenge for teachers, since, because it is broader issues, diverse and rich in concepts, they feel in their most, unprepared for this approach.
\end{abstract}

Keywords: Environmental Education. Interdisciplinarity. Contextualization of Education. 
Biasibetti, et al; Educação Ambiental.

\section{Introdução}

As questões ambientais vêm crescentemente ganhando repercussão em nível mundial. Diversos são os fatores que vêm intensificando esses problemas, tais como a expansão demográfica, o uso descontrolado dos recursos naturais, a poluição e o desmatamento.

Entretanto, a preocupação com os problemas ambientais apenas surgiu após a segunda metade do século XX, quando estes aspectos começaram a ganhar espaço no mundo político, passando a serem compreendidos como um problema mundial somente a partir 1960, BORGES (2003).

No Brasil, a Educação Ambiental (EA) passou a ser oficializada a partir da institucionalização da Lei Federal de no 6.938, sancionada em 1981, que criou a Política Nacional do Meio Ambiente (PNMA). Após uma longa caminhada na busca de melhorias no âmbito educacional, as escolas brasileiras passam a incluir a questão ambiental como parte integrante do currículo escolar, sendo orientadas pela Lei de Diretrizes e Bases da Educação Brasileira (LDB/96), que consideram o meio ambiente como um princípio fundamental da educação básica.

Segundo Tomasi (p.194,2000), neste final de século, "as crises se manifestam e entre elas percebemos que os recursos da Natureza estão se esgotando aos nossos olhos, tanto em quantidade como em qualidade, e deles depende a nossa sobrevivência". Para preservá-los e recuperá-los, imperiosa se faz uma prática de Educação Ambiental formal e informal que promova uma mudança urgente nas relações humanas e que estabeleça o comprometimento de cada cidadão com a gestão ambiental.

Diante destes aspectos, cabe salientar a importância que a abordagem de atividades relacionadas à EA possui no âmbito escolar, tornando-se excelentes alternativas de ensino, que podem, através de atividades trabalhadas no âmbito de sala de aula, sensibilizar os estudantes diante da importância de preservação do meio ambiente.

Na busca de melhorias na qualidade do meio ambiente, bem como a preservação dos seus recursos naturais, a escola surge como um excelente espaço de ensino-aprendizagem, uma vez que é neste que os sujeitos recebem os primeiros valores e princípios enquanto cidadão, responsáveis e comprometidos com o meio ambiente e a sociedade.

Entretanto, a educação escolar vem passando por múltiplos questionamentos relacionados com a qualidade de ensino e a forma de desenvolvimento de suas metodologias em todas as áreas do conhecimento. Muitas vezes as dificuldades sentidas pelos estudantes estão relacionadas com a forma em que os conteúdos didáticos são trabalhados no contexto de sala de aula, levando em consideração a descontextualização e a fragmentação dos conteúdos disciplinares. Nesta perspectiva, a educação ambiental é uma das áreas que mais carece de atividades interdisciplinares e contextualizadas, visto que na maioria das vezes, somente são abordadas no espaço de sala de aula, durante as disciplinas de ciências da natureza e biologia, ou até mesmo em datas comemorativas, como dia da água, meio ambiente e outros.

Nesta perspectiva, os currículos escolares precisam urgentemente adequarem-se a estas mudanças, buscando através de metodologias inovadoras enriquecer a educação e transformar o ambiente de sala de aula num espaço de aprendizagem, onde os estudantes sintam-se inseridos neste contexto.

Para isso, cabe aos educadores buscarem novos conhecimentos e metodologias inovadoras, baseadas em atividades práticas, relevantes, interessantes e interdisciplinares, que despertem o gosto de ensinar e aprender. Trabalhar com a EA desta forma, ganha mais sentido e significado, tornando a aprendizagem significativa e relevante, de modo que os estudantes possam compreender as relações existentes entre o ser humano, a natureza e o universo.

O presente trabalho foi desenvolvido em uma Escola Estadual de Ensino Fundamental e Médio localizada no município de Ijuí/RS, onde foi aplicado um questionário semiestruturado sobre a 
temática de EA no contexto de sala de aula e a interdisciplinaridade no processo de ensino. O objetivo geral desta pesquisa buscou compreender as dificuldades percebidas pelos professores durante o desenvolvimento das questões relacionadas à Educação Ambiental na escola. Sendo que os objetivos específicos consistiram em: realizar um estudo qualitativo sobre a concepção dos professores de uma escola estadual sobre a Educação Ambiental no contexto de sala de aula; verificar as dificuldades e os desafios sentidos pelos educadores durante o desenvolvimento das questões ligadas à Educação Ambiental durante as aulas e analisar as dificuldades sentidas para o trabalho interdisciplinar ligado a EA;

O instrumento de coleta de dados foi através de pesquisa semiestruturada aberta, na qual os professores puderam responder livremente a um questionário relacionado à temática de EA no contexto de sala de aula, expressando as suas dificuldades e os desafios durante a abordagem de atividades interdisciplinares relacionados às questões ambientais.

Segundo Manzini (1991), a entrevista semiestruturada está focalizada em um assunto sobre o qual o pesquisador pode confeccionar o roteiro das perguntas complementadas por questões inerentes às circunstâncias momentâneas à entrevista. Deste modo, o entrevistado pode responder aos questionamentos de forma livre, não estando às respostas condicionadas a uma padronização de alternativas objetivas.

\section{Revisão Bibliográfica}

\subsection{Os Problemas Ambientais do Século XXI}

O meio ambiente vem sendo utilizado pelos seres humanos como sua principal fonte de sobrevivência desde os primórdios da espécie, no qual trabalha e do qual retira alimento. Contudo, é recente a percepção de que os recursos naturais são findáveis, e a falta de gerenciamento adequado dos mesmos pode acarretar grave escassez.

Segundo Souza (2000) e Borges (2003), até a metade do século XX a degradação ambiental, a saúde humana e o bem-estar das comunidades não eram percebidos como fatores relacionados entre si e não havia a percepção de que essa ação pudesse colocar em riscos a vida no planeta.

Com o passar dos anos, o crescimento demográfico, a expansão agrícola e os avanços tecnológicos intensificaram-se ainda mais os problemas ambientais, e com isso começaram a surgir as mudanças climáticas, o aquecimento global e efeito estufa. Como consequência destes fatores, o desequilíbrio dos ecossistemas começou a interferir e prejudicar a vida dos seres humanos, animais e plantas.

Atualmente, as consequências pelo uso descontrolado dos recursos naturais vêm tornando-se frequentes uma vez que o meio ambiente não consegue suprir a demanda de recursos naturais que são extraídos da natureza. Desta forma, os seres humanos tornaram-se os principais causadores da problemática ambiental, uma vez que, através de suas ações diárias, tem intensificado a produção desordenada de resíduos sólidos no meio ambiente, e com isso surgem os problemas relacionados à poluição do solo, água e ar, interferindo assim no desequilíbrio dos ecossistemas.

Para Brasil (2007), os seres humanos estão sentindo na pele as consequências do uso desenfreado dos recursos naturais, da qual surge a urgente necessidade de transformação para a superação da problemática ambiental, a desigualdade social, a apropriação da natureza e da própria humanidade, como objetos de exploração e consumo.

$\mathrm{Na}$ busca de minimizar a atual problemática ambiental ocasionada pelas interferências humanas na natureza, a EA surge como uma excelente ferramenta de ensino, podendo através de um trabalho didático-educativo, sensibilizar a população da importância de conservação dos ecossistemas, buscando através de ações sustentáveis, evitar o desperdício e o consumo desnecessário. 


\subsection{A Abordagem da EA em Sala de Aula e a Legislação}

A legislação ambiental é um instrumento que auxilia na conservação dos recursos naturais, através de um conjunto de normas e princípios buscam assegurar os recursos naturais mantendo o equilíbrio dos ecossistemas.

Segundo os Parâmetros Curriculares Nacionais (PCNs), a preocupação em modificar as concepções educacionais relacionadas à educação e o meio ambiente não é novidade, sendo discutida desde a década de 70 pelas Instituições Federais, a partir do crescimento dos movimentos ambientais, passou-se a utilizar a expressão de "Educação Ambiental" no contexto educacional, que buscava conscientizar todos os setores da sociedade para as questões relacionadas ao meio ambiente. Entretanto, somente em 1981 foi instituída a Politica Nacional de Meio Ambiente. No Brasil, a legislação foi estabelecida através das medidas implementadas pela UNESCO, na qual foi então oficializada e institucionalizada pela Lei Federal de no 6.938 e sancionada em 1981, que criou a Política Nacional do Meio Ambiente (PNMA).

Desta forma, a Lei 6938/1981 estabelece os seguintes objetivos: preservação, melhoria e recuperação da qualidade ambiental propícia à vida, visando assegurar, no País, condições ao desenvolvimento socioeconômico, aos interesses da segurança nacional e à proteção da dignidade da vida humana, atendendo ao seguinte princípio:

$X$ - educação ambiental a todos os níveis de ensino, inclusive a educação da comunidade, objetivando capacitá-la para participação ativa na defesa do meio ambiente.

De acordo com a Constituição Brasileira de 1988, artigo 225, $1^{\circ}$ parágrafo, item VI, o Poder Público deve "promover a educação ambiental em todos os níveis de ensino e a conscientização pública para a preservação do meio ambiente" (BRASIL, 1990).

A Política Nacional de Educação Ambiental, instituída pela Lei n o 9.795 de 27 de abril de 1999, no capítulo I, artigo $1^{\mathrm{o}}$ conceitua Educação Ambiental como os processos por meio dos quais o indivíduo e a coletividade constroem valores sociais, conhecimentos, habilidades, atitudes e competências voltadas para a conservação do meio ambiente, bem de uso comum do povo, essencial à sadia qualidade de vida (BRASIL, 1999, p.5).

Contudo, as escolas passaram então a serem orientadas para a inserção da Politica Ambiental nos currículos escolares, a partir da "Lei de Diretrizes e Bases da Educação Brasileira (LDB/96), a qual passou a considerar a compreensão do ambiente natural como fundamental para a educação básica" (BRASIL, 2004, p. 02). Desta forma, a inclusão da área de Meio Ambiente como parte inerente aos currículos escolares, passou a fazer parte do contexto de sala de aula, tendo como amparo os PCNs.

A Política Nacional de Educação Ambiental busca através de suas concepções pedagógicas, propor o desenvolvimento dos conhecimentos disciplinares através de um pluralismo de ideias com amparo no processo da interdisciplinaridade. A lei ainda determina que a EA não seja trabalhada na forma isolada no contexto das aulas de ciências ou biologia, mas que faça parte do currículo das diversas áreas do conhecimento.

Após anos de discussão sobre a implantação de um Código Estadual de Meio Ambiente no Estado do Rio Grande do Sul, no ano de 2000 fica então instituída uma nova Lei. A Lei nº. 11.520, de 03 de agosto de 2000 tem como principal objetivo atender os todos os assuntos relacionados às condições ambientais da fauna, flora, solo, agua e ar. Este código propõe ainda penalidades por autos de infração que sejam cometidas e que degradem ou alterem as de vida dos ecossistemas.

Propõe ainda segundo o Art. 27 do referido, é de competência do Poder Público promover a educação ambiental em todos os níveis de sua atuação e a conscientização da sociedade para a preservação, conservação e recuperação do meio ambiente, considerando:

I - a educação ambiental sob o ponto de vista interdisciplinar;

II - o fomento, junto a todos os segmentos da sociedade, da conscientização ambiental; 
III - a necessidade das instituições governamentais estaduais e municipais de realizarem ações conjuntas para o planejamento e execução de projetos de educação ambiental, respeitando as peculiaridades locais e regionais (RIO GRANDE DO SUL, 2000).

A partir dos pressupostos legais, os professores precisaram adequar-se às novas propostas, passando a desenvolver a EA no decorrer de suas disciplinas curriculares. No entanto, por se tratar de um campo ainda cheio e incertezas, a EA ainda sofre uma enorme resistência para sua abordagem em sala de aula, tendo em vista a dificuldade sentida pelos professores durante a inserção de atividades relacionadas ao meio ambiente, visto que muitos não obtiveram durante a sua formação acadêmica conceitos relacionados à conservação, preservação e sustentabilidade do planeta. Por sentirem-se despreparados para essa abordagem, a temática ambiental acaba sendo apenas trabalhada durante as disciplinas de ciências da natureza e biologia.

Para BOFF et al, 2011, a Educação Ambiental tem chamado atenção quanto à necessidade de propostas, no meio escolar, que promovam a melhoria das relações do ambiente e da qualidade de vida do planeta. Uma das dificuldades apresentadas, para o enfrentamento da problemática ambiental nas escolas, refere-se aos empecilhos teóricos e práticos para transpor o paradigma disciplinar e desenvolver concepções e práticas que incorporem o paradigma interdisciplinar.

Sabe-se que a escola desempenha um papel fundamental na vida dos cidadãos durante o processo de aprendizagem, pois mesmo que ela não mude a sociedade, "pode, partilhando através de projetos com segmentos sociais que assumem os princípios democráticos, articulando-se a eles, constituir-se não apenas como espaço de reprodução, mas também como espaço de transformação" (BRASIL, 2007, p. 23).

Souza e Galiazzi, afirmam que:

\begin{abstract}
Em relação à Educação Ambiental, provavelmente seja consensual o desejo de que as escolas se constituam em espaços para a articulação de ações internas e com outros segmentos da sociedade; que privilegiem a formação de valores, questionando a ênfase exacerbada em informações e conceitos; que construam caminhos em ações educativas sustentadas especialmente no diálogo, respeito ao outro, cooperação, solidariedade e coletividade. A EA, em tal perspectiva, implica assumirmos a escola enquanto espaço privilegiado para a discussão de questões para uma melhor compreensão e apropriação de significados a respeito das relações entre seres humanos e ambiente, (2007, p. 299).
\end{abstract}

A partir disso, os currículos escolares vêm passando por algumas reformas de estruturação, pela qual, buscam através de atividades interdisciplinares envolverem todas as áreas do conhecimento, fortalecendo o processo de sensibilização e conscientização dos estudantes diante das questões ambientais.

O professor nesse sentido exerce a papel de auxiliar nesse processo de ensino, sensibilizando os estudantes da necessidade de mudanças de atitudes, que busquem a sustentabilidade e o equilíbrio dos ecossistemas, contribuindo na formação de cidadãos comprometidos com o presente e o futuro do país (ROA et al, 2009).

Para BOFF (2010) ao considerar a EA como parte essencial do currículo escolar, algumas questões podem ser estudadas e debatidas em espaços formais, como a escola, produzindo novas concepções de forma que os estudantes passem a se interessar por elas, entendê-las e agir de forma consciente, numa perspectiva de provocar mudanças de atitudes que venham a contribuir para a melhoria da qualidade ambiental.

\title{
2.3. A Educação Ambiental e a Interdisciplinaridade
}

Sabe-se que a interdisciplinaridade constitui-se uma excelente alternativa para desfragmentação do ensino escolar, tornando o saber enriquecedor, possibilitando trabalhar de forma integrada com todas as áreas do conhecimento, auxiliando no desenvolvimento dos conteúdos e na compreensão dos estudantes sobre conteúdos disciplinares. 
Segundo Fazenda (2001), o pensar interdisciplinar parte da premissa de que nenhuma forma de conhecimento é em si mesma racional. Tenta, pois, o diálogo com outras formas de conhecimento, deixando-se interpenetrar por elas. A abordagem da EA no contexto da sala de aula de maneira interdisciplinar caracteriza-se como um importante instrumento de ensino, o qual possibilita fortalecer o trabalho de sensibilização dos estudantes frente aos aspectos do meio ambiente, de modo possam perceber a relação existente entre a natureza e as diversas áreas disciplinares.

No entanto, trabalhar com a interdisciplinaridade no contexto de sala de aula, muitas vezes não é uma tarefa fácil, visto que grande parte dos professores encontra-se acomodados a metodologias tradicionais, lineares, descontextualizadas e distantes do cotidiano real dos estudantes. Deste modo, sentem-se inseguros e incomodados com a ideia de mudança na forma de ensino, encontrando dificuldades em buscar novas metodologias que apontem melhorias na qualidade da aprendizagem dos estudantes. Preferem continuar no isolamento da sua disciplina, trabalhando apenas com os conceitos disciplinares, os quais possuem maior domínio e conhecimento.

Segundo a Lei de Diretrizes e Bases da Educação Nacional (LDB) 1996, o ensino expressa uma grande urgência na sua reorganização curricular a fim de dar conta dos desafios estabelecidos pela sociedade. Para isso torna-se necessário superar a fragmentação e descontextualização do ensino brasileiro, priorizando o estabelecimento de relações que permitam a produção de aprendizagens significativas.

No mesmo sentido, os PCNs também salientam a importância da abordagem de um currículo contextualizado, que contemple os aspectos interdisciplinares na sua totalidade e que vá além da justaposição de disciplinas, evitando o desperdício de informações de modo a se perder em generalidades. O trabalho interdisciplinar necessita "partir da necessidade sentida pelas escolas, professores e alunos, de explicar, compreender, intervir, mudar, prever algo que desafia uma disciplina isolada e atrai a atenção de mais de um olhar, talvez vários" (BRASIL, 1999, p. 88-89).

Na perspectiva escolar, a interdisciplinaridade não tem a pretensão de criar novas disciplinas ou saberes, mas de utilizar os conhecimentos de várias disciplinas para resolver um problema concreto ou compreender um determinado fenômeno, sobre diferentes pontos de vista. Em suma, a interdisciplinaridade tem uma função instrumental. Trata-se de recorrer a um saber diretamente útil e utilizável para responder às questões e aos problemas sociais contemporâneos

Para Martins (2001), o educador que tem o papel de atuar como o agente de transformação social, procurando o melhor caminho para vencer o desafio de mudar sua própria forma de pensamento. Isso significa possibilitar uma formação aos estudantes, que permita compreender os conhecimentos científicos, fundamentado na interdisciplinaridade e contextualização, possibilitando realizar uma ponte de conexão entre os conteúdos trabalhados e compreensões acerca da realidade.

A EA precisa ultrapassar as barreiras do ensino fragmentado, conteudista e linear, interagindo com a interdisciplinaridade, repensando suas formas de ensino, enxergando a relação existente entre o ser humano e a natureza.

Para BOFF et al, 2011, a interdisciplinaridade precisa ser compreendida pela necessidade de mudanças no contexto escolar, valorizando o trabalho em conjunto e possibilitando melhorias ao ambiente educacional. Trabalhar de modo coletivo traz contribuições significativas para o entendimento de questões vivenciadas pelos estudantes. Um coletivo, em parceria colaborativa, pode auxiliar mutuamente tanto nos entendimentos específicos disciplinares quanto nas múltiplas possibilidades de interação e construção de aprendizagem.

\subsection{Metodologias Inovadoras do Currículo Escolar}

As áreas das Ciências da Natureza e Biologia sempre foram muito questionadas, dada sua complexidade de conteúdos que dificultam a compreensão das concepções científicas do mundo natural. Atualmente essas disciplinas ainda sofrem diante desses obstáculos, visto a grande dificuldade de aprendizagem dos estudantes nas áreas das Ciências e Biologia. Acredita-se que esses 
fatores estejam intimamente relacionados à falta de investimentos pelos órgãos públicos, bem como, a descontextualização dos conteúdos, a linearidade e a fragmentação do ensino.

O desenvolvimento da EA no contexto de sala de aula pode constituir uma excelente alternativa de abordagem das questões relacionadas aos aspectos do ser humano e a natureza, promovendo a melhoria das relações do estudante entre o meio ambiente e da qualidade de vida do planeta, chamando a atenção para as dificuldades apresentadas nas escolas, através dos empecilhos teóricos e práticos para transpor o paradigma disciplinar e desenvolver concepções e práticas relacionadas às questões ambientais (BOFF et al, 2011).

Para Maldaner (2000 e 2001), estudos sobre situações reais e contextualizadas, despertam curiosidade, participação e empenho dos estudantes para aceitar e estruturar conhecimentos científicos escolares, ampliando saberes, realizando pontes entre conhecimentos pré-estabelecidos com os conteúdos trabalhados em sala de aula, a fim de construir uma consciência crítica e necessária à melhoria da qualidade de vida. O autor ainda salienta que ao realizar uma análise reflexiva sobre o ensino de Ciências, Biologia, Química e Física, é notável que o perfil do trabalho exercido em sala de aula nestes componentes curriculares está rigorosamente marcado pelo uso exclusivo do livro didático, tendo como características o conteudismo, fragmentação, linearidade, descontextualização e ausência da articulação entre as demais áreas curriculares.

Diante destes aspectos, cabe salientar a importância da abordagem de metodologias inovadoras em todas as áreas do conhecimento, permitindo os estudantes compreender os conteúdos disciplinares através de atividades práticas, interdisciplinares, inovadoras e contextualizadas.

Sabe-se que o livro é um recurso didático importante, mas é essencial reconhecer também que o modelo tradicional de ensino, ainda muito utilizado pelos educadores nas escolas, torna difícil para o aluno relacionar o conteúdo abordado com sua realidade. Isto ocorre porque muitos dos livros adotados apresentam conceitos pouco esclarecedores e que nem sempre contribui para a percepção da complexidade das ciências pelos estudantes.

Para Vasconcellos (1998), as metodologias tradicionais de ensino utilizadas no contexto de sala de aula produzem pouco resultado na aprendizagem dos estudantes e como consequência disso o conhecimento acaba não sendo construído e o aluno encontra-se em uma posição secundária no processo de ensino-aprendizagem.

De acordo com os PCN's (2000), partindo dos princípios definidos na Lei de Diretrizes e Bases (LDB), o Ministério da Educação, num trabalho em conjunto com educadores, buscou um novo perfil para o currículo escolar, apoiado em competências básicas para a inserção de nossos jovens na vida adulta.

Desta forma, o ensino que antes era descontextualizado, compartimentalizado e baseado no acúmulo de informações, ganhou significado mediante a contextualização e a interdisciplinaridade, que através de novas propostas, passou a incentivar o raciocínio e despertar o interesse dos estudantes.

\subsection{Atividades Práticas como Ferramenta Instigadora do Processo de Aprendizagem}

A escola exerce um papel fundamental para a formação do educando, visto que é no ambiente escolar que os conhecimentos informais pré-estabelecidos pelos estudantes tornam-se fundamentais para sua aprendizagem formal. Para tanto, faz-se necessário a utilização de diferentes metodologias e estratégias que auxiliem o desempenho desse processo de ensino, relacionando os conteúdos disciplinares apreendidos em sala de aula com as vivências dos alunos.

Segundo Silva, et al 2009, o professor tem a importante função de planejar atividades práticas que facilitam a compreensão dos conteúdos teóricos disciplinares, estimulando-os a questionar, responder, observar, explorar, analisar, comparar e compreender a situação problema, levando ao 
desenvolvimento de novos conhecimentos, uma vez que o acesso ao conhecimento novo ocorre a partir do pré-existente.

No entanto, o uso de atividades práticas no ambiente escolar ainda é muito escasso na maioria das escolas, uma vez que, os professores não se sentem preparados e motivados para a realização de atividades em laboratórios.

A falta de atividades dinâmicas, motivadoras e interdisciplinares, relacionadas aos conteúdos curriculares, promove a insatisfação, ausência de participação e interesse dos estudantes, o que inviabiliza o processo de aprendizagem.

Segundo Fagundes (2007), muitas são as criticas redigidas a carência de atividades práticas no ambiente de sala de aula, alguns professores justificam suas aulas basicamente conteudista, como uma sequência de dificuldades cotidianas, ou seja, a ausência de local apropriado (o amedrontador laboratório) e a escassez de material e equipamentos adequados. Não há dúvidas de que estes são fatores limitantes, mas não deveriam causar impedimento, é preciso buscar alternativas que viabilizam a realização de atividades motivadoras, utilizando materiais alternativos, usufruindo dos espaços internos e externos que a escola dispõe.

Para os PCNs os procedimentos fundamentais para o ensino precisam permitir investigação científica, visando o desenvolvimento da ciência e da tecnologia e da criação e difusão da cultura, e, desse modo, desenvolver o entendimento do homem e do meio em que vive. O ensino deve ir além da descrição, precisa constituir nos alunos a capacidade de analisar, explicar, prever e intervir. Estes objetivos somente são alcançáveis se as disciplinas integradas em áreas de conhecimento puderem contribuir cada uma com sua especificidade, para o estudo comum de problemas concretos, ou através do desenvolvimento de projetos de investigação, ou práticas de ação (BRASIL, 2000).

Portanto, as possibilidades de aprendizagem proporcionadas pelas atividades práticas dependem de como estas são propostas e desenvolvidas em sala de aula, uma vez que, dependendo de sua condução, as atividades práticas podem favorecer, entre os estudantes, modos de pensar, atitudes e até interconexões entre Ciência, tecnologia, ambiente e sociedade. Assim, tais atividades podem aproximar o ensino à Ciência, que costuma ser apresentada em uma visão deformada durante as aulas (CACHAPUZ, 2005).

\subsection{A Importância do Professor Pesquisador e Reflexivo}

Diante de vários aspectos, a formação do professor pesquisador e reflexivo é extremamente importante para o processo de ensino e a formação dos estudantes, uma vez que, a partir da pesquisa e reflexão o educador tem a oportunidade de rever seus conceitos, aprimorar suas práticas e refletir as suas aulas. A aprendizagem e o conhecimento precisam ser construídos e reconstruídos constantemente, na medida em que o professor vai apropriando-se da pesquisa e interagindo com o contexto real.

Conforme Freire (1996, p.32):

\footnotetext{
Não há ensino sem pesquisa e pesquisa sem ensino. Esses que fazeres se encontram um no corpo do outro. Enquanto ensino continuo buscando e reprocurando. Ensino porque busco, porque indaguei, porque indago e me indago. Pesquiso para constatar constatando, intervenho, intervindo educo e me educo. Pesquiso para conhecer o que ainda não conheço e comunicar ou anunciar a novidade.
}

Para Silva (2012), a pesquisa permite ao professor estabelecer relações autônomas na medida em que, ao ir desenvolvendo suas práticas e suas necessidades, envolve-se num movimento que o permite apropriar-se em maior profundidade de sua ação e da teoria desta ação, assim avançando na necessária coerência entre o fazer e o pensar sobre/do fazer. 
A pesquisa é um elemento essencial à formação e atuação docente, uma vez que, quando atrelada ao processo de reflexão sobre a atuação no contexto escolar, esta permite o professor analisar, refletir e rever seus conceitos, compreendendo suas dificuldades e as dos próprios estudantes.

Entretanto, diversas são as dificuldades e anseios sentidos pelos educadores no cotidiano real da sala de aula. Tornar-se um pesquisador reflexivo não é uma tarefa fácil e nem deve ser compreendida no isolamento das disciplinas curriculares. Segundo BOFF et al, 2011, para constituir-se um professor-pesquisador é essencial estabelecer interações entre os sujeitos, compartilhando experiências distintas. A reflexão coletiva estimula o docente a serem autor e ator de seu processo de ensino e aprendizagem, pode contribuir para a transformação das práticas educativas, no espaço real de sala de aula, num processo de permanente construção e reconstrução de saberes.

Para Demo (2000) a pesquisa quando bem compreendida, serve para superar os entraves do dia-dia, instigando a formação de estudantes e aprimoramento de professores questionadores. Deste modo o autor reafirma que, ao passar pelo processo de pesquisa, o sujeito tem oportunidade de desenvolver o pensamento crítico, exercitar a reflexão, tornando-se produtor de conhecimentos e não só um mero reprodutor de informações. Para isso, é imprescindível a participação, atuação e envolvimento do educador no processo de pesquisa, considerando que esse método de formação envolve o saber pensar criticamente e refletir suas metodologias e práticas.

No mesmo sentido, Galiazzi e Moraes (2002) também explicitam que a pesquisa propicia a qualidade de formação tanto do educador e educandos, uma vez que promove a "capacidade de intervenção qualificada nas realidades educativas, tanto em sentido restrito de sala de aula como no contexto mais amplo".

Ao realizar uma análise reflexiva sobre as concepções dos autores diante da temática da pesquisa e reflexão no contexto escolar, é possível compreender a importância dessa abordagem para o melhoramento das atividades didáticas e disciplinares, uma vez que, a pesquisa é instigante, faz o ser humano buscar respostas, repensar conceitos. Deste modo, o professor pesquisador torna-se investigativo e reflexivo, deixando de ser reprodutor de conhecimento para atuar como autor de suas próprias práticas educativas, possibilitando aos educandos uma aprendizagem satisfatória.

A EA não se restringe apenas ao espaço escolar, mas compreende-se que a escola é um espaço privilegiado que pode utilizar de concepções curriculares inovadoras que contemplem os conteúdos disciplinares necessários, para cada nível de ensino e que ao mesmo tempo estimulem a aquisição de novas condutas pelos educandos.

Nesse sentido as atividades relacionadas à EA precisam ser abordadas em sala de aula desde o inicio da vida escolar, para que os estudantes possam começar desde cedo a reconhecer a importância da preservação do meio ambiente para a manutenção de todas as formas de vida.

A escola e os professores exercem um papel fundamental na formação dos estudantes, podendo através de atividades educativas de EA, sensibilizá-los diante da importância na conservação do meio ambiente.

Atualmente, a escassa participação dos estudantes no contexto de sala de aula e a falta de interesse pelos assuntos abordados intensificam o déficit de aprendizagem e avanço do ensino.

$\mathrm{O}$ trabalho, quando desenvolvido em conjunto, a partir de assuntos relevantes, contextualizados e inter-relacionados com o cotidiano dos estudantes, fortalece o vinculo entre o professor-aluno-conteúdo, despertando o interesse em aprender e compreender os assuntos estudados, sentindo-se inserido neste contexto. Segundo os Parâmetros curriculares Nacionais do Ensino Médio,

a integração dos diferentes conhecimentos pode criar as condições necessárias para uma aprendizagem motivadora, na medida em que ofereça maior liberdade aos professores e alunos para a seleção de conteúdos mais diretamente relacionados aos assuntos ou problemas que dizem respeito à vida da comunidade. Todo conhecimento é socialmente comprometido e não há conhecimento que possa ser aprendido e recriado se não se parte das preocupações que as pessoas detêm. O distanciamento entre os conteúdos programáticos e a experiência dos alunos certamente responde pelo desinteresse e até mesmo pela deserção que constatamos em nossas escolas. Conhecimentos selecionados a priori tendem a se perpetuar nos rituais escolares, sem 
passar pela crítica e reflexão dos docentes, tornando-se, desta forma, um acervo de conhecimentos quase sempre esquecidos ou que não se consegue aplicar, por se desconhecer suas relações com o real (2000, p. 22).

Neste sentido, dentro da perspectiva de sala de aula, a interdisciplinaridade precisa trazer a pretensão de utilizar dos conhecimentos adquiridos dentre as várias áreas do conhecimento, auxiliando no processo de aprendizagem dos sujeitos envolvidos.

Para isso, os professores precisam estar abertos às mudanças que proporcionem melhorias na qualidade do ensino, buscando através de ferramentas de pesquisa trazer para o ambiente de sala de aula, atividades motivadoras, contextualizadas e interdisciplinares, de modo que os estudantes sintam-se parte do contexto, instigados a buscar novos conhecimentos, realizar pesquisas bibliográficas, leituras, discutindo e interagindo com os colegas. Para que o trabalho tenha resultado e a aprendizagem aconteça, o professor precisa ser o agente desse processo de ensino.

\section{Metodologia}

A pesquisa foi desenvolvida em uma Escola Estadual de Ensino Fundamental e Médio do Município de Ijuí/RS. Para responder aos questionários, optou-se pela escolha das seguintes áreas do conhecimento: Ciências, Biologia, Química e Física. Desta forma, participaram da pesquisa 5 professores, sendo um da área de Ciências, dois de Biologia, um de Química e um de Física.

O instrumento de coleta de dados deu-se na forma de um questionário, o qual continha 12 questões abertas. A pesquisa buscou compreender a forma como os professores trabalham as questões relacionadas com a EA no contexto de sala de aula.

Através do questionário aplicado, buscou-se verificar as dificuldades sentidas pelos professores durante processo de sensibilização dos estudantes frente às questões ambientais. $\mathrm{O}$ questionário desenvolvido está disponível no apêndice A final do presente trabalho.

Os pressupostos metodológicos têm como base os argumentos da pesquisa qualitativa da Análise textual Discursiva de Moraes e Galiazzi (2007). Para sistematizar as informações apresentadas a partir dos questionários, as respostas dos mesmos foram digitalizadas, posteriormente analisados e explanados nos resultados e discussões desta pesquisa. Os professores puderam responder ao o questionário de forma livre, de acordo com suas compreensões e entendimentos sobre os assuntos abordados.

Para auxiliar no processo de elaboração desta pesquisa foi realizado um levantamento bibliográfico utilizando-se de autores que abordam a temática, a fim de auxiliar na construção da fundamentação teórica sobre a Educação Ambiental e a interdisciplinaridade em sala de aula.

\section{Resultados e Discussão}

A EA não deve apenas se restringir ao espaço de sala de aula, mas compreende-se que é na escola o ambiente privilegiado em que os estudantes constituem-se cidadãos conscientes e responsáveis com o meio ambiente e a sociedade, neste sentido, os professores exercem um papel fundamental, contribuindo e auxiliando para esta formação.

A fim de preservar a identidade dos cinco professores participantes, os mesmos foram codificados como P1, P2, P3, P4 e P5.

Como forma de discussão, as respostas dos questionários respondidos pelos professores, foram avaliadas e comentadas a partir de um embasamento teórico-reflexivo que permitiu auxiliar na compreensão e na construção dos resultados desta pesquisa. Os questionários e as respostas estão disponíveis nos APÊNDICES A desta pesquisa. 
De acordo com as respostas dos professores sobre as questões 1, 2 e 3 (ver Apêndice), é possível perceber que todos possuem uma visão global sobre a EA e reconhecem a suma importância da abordagem desses assuntos no contexto das suas disciplinas.

Segundo os Parâmetros Curriculares Nacionais do Ensino Médio, a abordagem das questões ambientais já ganhou espaço em todas as escolas, inerente aos currículos escolares como tema transversal. A abordagem das questões ambientais deve ser trabalhada de modo em que a teoria e a prática se complementem e vice-versa, considerando o modo de interação entre ser humano e a natureza, por meio de suas relações sociais, do trabalho, da ciência, da arte e da tecnologia.

Para BOFF et al, 2011, p.307,

As discussões sobre a Educação Ambiental têm chamado atenção quanto à necessidade de
propostas no ambiente escolar, que promovam a melhoria das relações do ambiente e da
qualidade de vida do planeta. Uma das dificuldades apresentadas para uma prática eficaz e o
enfrentamento da problemática ambiental nas escolas, refere-se aos empecilhos teóricos e
práticos para transpor o paradigma disciplinar e desenvolver concepções e práticas que
incorporem o paradigma interdisciplinar.

Em relação aos questionamentos do trabalho interdisciplinar, percebe-se que os professores demonstram-se inseguros para o desenvolvimento da interdisciplinaridade, alegando a falta de tempo de planejamento, como um dos principais empecilhos que dificultam essa abordagem, podendo ser evidenciado nas respostas dos professores P1, P2 e P3:

(...) P1 Quando é trabalhado sobre uma temática, a vivência e os conceitos de outras disciplinas acabam se fazendo presentes para complementar todo o entendimento. Se o planejamento é feito na área, essa interdisciplinaridade acontece com o aprofundamento conceitual. Sempre que possível procuro contemplar conceitos de outras disciplinas, mas falta planejamento no conjunto de todos os professores.

(...) P2 Muito difícil, pois os professores têm carga horária distribuída em vários turnos e várias escolas, o que torna difícil (quase impossível) encontros de planejamento.

(...) P3 Tem alguns projetos que conseguem transpor todas as disciplinas, principalmente os ambientais, outros nem tanto, porém não devemos forçar a interdisciplinaridade se não dominamos o assunto, para não cometer erros e tornar o trabalho algo massacrante para o aluno, e um fracasso no processo de aprendizagem.

Para BOFF et al, 2011, p. 87,

\begin{abstract}
A interdisciplinaridade decorre da necessidade de compreensão das situações reais e complexas do contexto escolar, valorizando o trabalho em conjunto, independente desta ou daquela disciplina, o coletivo traz contribuições importantes para o entendimento de questões vivenciais dos estudantes. Um coletivo, em parceria colaborativa, pode se auxiliar mutuamente tanto nos entendimentos específicos disciplinares quanto nas múltiplas possibilidades de interação e construção de aprendizagem envolvendo questões sociais, culturais, ambientais e de saúde, conforme proposto pelos PCN.
\end{abstract}

Deste modo, cabe ressaltar a importância do planejamento curricular para a organização das informações entre as várias disciplinas, conceitos e aprendizagens, o trabalho em conjunto auxilia através da troca de experiências, novos conhecimentos e aprendizagens, de forma que a interdisciplinaridade sobrevenha.

Considerando as respostas expressas da questão 5 ver Apêndice) sobre o papel da escola como agente motivador e de amparo ao desenvolvimento de projetos interdisciplinares, os professores demonstraram sentir-se amparados quanto ao desenvolvimento de propostas de ensino interdisciplinares, entretanto a questão que mais interfere nesse processo continua sendo a falta de tempo e a insegurança, conforme pode ser verificado na resposta de um dos professores: (...) P3 Sim, a escola sempre está aberta a novas propostas e metodologias inovadoras de ensino. Entretanto nem sempre é fácil trabalhar de modo interdisciplinar.

A partir desta concepção, a escola exerce um papel fundamental na organização e planejamento do trabalho interdisciplinar, atuando como o agente motivacional que vai muito além 
de ensinar conteúdos disciplinares, a escola deve oportunizar a reflexão, aprendizagens, habilidades e valores.

Para a compreensão dos assuntos relacionados ao meio ambiente, as questões 6, 7, 8, 9 e 10 (ver Apêndice) buscam sistematizar a concepção dos professores sobre os aspectos da EA e sustentabilidade.

As respostas da questão 6, buscaram avaliar a compreensão dos educadores sobre a temática de sustentabilidade. De acordo com as respostas dos professores P4 e P5 podem ser evidenciadas tais explanações:

(...) P4 A palavra sustentabilidade é muito abrangente e dizer que ações sustentáveis são de fato sustentáveis, é muito relativo. No ponto de vista educativo a sustentabilidade tem gerado muitos debates e sugestões, porém mudanças de fato são muito poucos. Mudanças de grande impacto ainda não observei.

(...) P5 Sustentabilidade, é algo muito complexo e difícil de alcançar, acredito que falta muito para vivermos em um mundo sustentável, falta conscientização de todos, reduzir o consumo de lixo, eletrônicos $e$ desperdícios. A sustentabilidade é viver sem interferir e alterar as condições do meio ambiente, sem degradação, poluição e descaso.

Através dos relatos evidenciados acima, é possível compreender que os educadores possuem concepção formada sobre os conceitos de sustentabilidade, entretanto, consideram o assunto amplo e complexo, que no contexto de sala de aula geram muitas discussões, porém na prática poucas mudanças.

Entretanto, a sustentabilidade precisa ser compreendida como uma ferramenta necessária para o equilíbrio e conservação dos ecossistemas, na qual as pequenas atitudes são importantes, independentemente do tempo que as mudanças levem a surgir efeito, é interessante buscar viver em constante equilíbrio com o meio minimizando a problemática ambiental que a natureza vem sofrendo.

A partir dos relatos expressos pelos professores em relação às questões 7 e 8 , é possível perceber que a abordagem de atividades relacionadas à EA é sempre bem aceita pelos estudantes, gerando muitas discussões. No entanto, as mudanças de hábitos e atitudes acabam gerando desconforto e acabam muitas vezes não acontecendo na prática. Segue algumas das respostas dos professores sobre esses questionamentos:

(...) P1 Quanto às manifestações, envolvimento nas atividades, os estudantes fazem boas reflexões o mais difícil são as ações concretas. Nesse sentido o trabalho precisa ser contínuo e por todos.

(...) P4 Na maioria das vezes eles não se dão conta da importância preservação, não tem a percepção de que os recursos naturais podem findar. Precisam perceber que as mudanças de atitude precisam acontecer.

Tendo em vista que todas as ações/alterações sobre o meio ambiente são de responsabilidade de todos, o trabalho da EA precisa ser compreendido como parte integrante da vida dos seres humanos, e que necessita ser exercido na escola, em casa e na sociedade, independentemente do retorno que as atividades ambientais exerçam sobre as pessoas. É dever de todos como cidadãos, comprometer-se com o meio ambiente e mesmo que as mudanças custem a acontecer, por menor que elas sejam, no todo isso sempre fará a diferença.

Diante dos questionamentos das questões 9 e 10 sobre os resíduos considerados mais prejudiciais a saúde humana e como o mau gerenciamento pode interferir no meio ambiente, os professores elegeram diversos tipos de resíduos extremamente preocupantes, os quais podem ser evidenciados nas respostas dos professores P1, P2 e P3:

(...) P1 Resíduos com componentes químicos, metais pesados e resíduos hospitalares.

(...) P2 Por metais pesados, pois podem contaminar todo o ambiente e na medida em que nos contaminamos causam uma série de problemas.

(...) P3 O lixo que não pode ser reciclado ou reutilizado. Também o lixo tóxico, químico e que não podem ser neutralizado, os quais podem ocasionar a contaminação do solo e da água. Proliferação de insetos vetores e doenças. 
A problemática ambiental relacionada com os resíduos sólidos vem gerando muitas discussões acerca da sua utilização e destino correto dos materiais, uma vez que, o mau gerenciamento destes resíduos implica em sérios prejuízos ao meio ambiente. Segundo Fadini \& Fadini:

\begin{abstract}
Os resíduos gerados por aglomerações urbanas, processos produtivos e mesmo em estações de tratamento de esgoto são um grande problema, tanto pela quantidade quanto pela toxicidade de tais rejeitos. A solução para tal questão não depende apenas de atitudes governamentais ou decisões de empresas; deve ser fruto também do empenho de cada cidadão, que tem o poder de recusar produtos potencialmente impactantes, participar de organizações não governamentais ou simplesmente segregar resíduos dentro de casa, facilitando assim processos de reciclagem. $\mathrm{O}$ conhecimento da questão do lixo é a única maneira de se iniciar um ciclo de decisões e atitudes que possam resultar em uma efetiva melhoria de nossa qualidade ambiental e de vida (2001, p. 9).
\end{abstract}

Portanto, os seres humanos precisam repensar suas atitudes, rever seus conceitos e comprometerem-se com o meio ambiente, evitando desperdícios e colaborando com o destino correto dos resíduos produzidos pelas ações humanas.

De acordo com o questionamento 11 (ver Apêndice), referente à abordagem de atividades relacionadas ao meio ambiente em sala de aula. Nas respostas dos professores P2 e P3 podem ser observadas claramente suas concepções:

(...) P2 As atitudes dos alunos demonstram que não são responsáveis na escola e na família, descartam de forma incorreta os resíduos sólidos e não se preocupam com o desperdício de materiais.

(...) P3 Falta tempo, interesse dos alunos. Falta de um projeto que envolva toda a escola.

Com base nos argumentos dos professores P2 e P3, percebe-se que os professores mostram-se pouco motivados para a abordagem das questões ambientais, uma vez que julgam as atitudes dos alunos como falta de interesse e comprometimento com o meio ambiente, tanto da escola como em suas casas. A falta de um projeto interdisciplinar, que envolva o coletivo de professores pode ser a principal causa do desinteresse dos estudantes pelas questões ambientais. As mudanças precisam acontecer partindo do principio de que, os educadores devem buscar metodologias inovadoras, contextualizadas e práticas que envolvam o estudante no contexto das suas disciplinas, somente assim a aprendizagem e o interesse dos estudantes serão percebidos no dia-dia de sala de aula.

Para as respostas dos professores referente à questão 12 (ver Apêndice), se eles consideram estar contribuindo para reduzir os problemas ambientais a curto e longo prazo, é possível perceber que todos consideram que sim, no entanto não acham o suficiente e acreditam que ainda há muito que ser feito para que as mudanças aconteçam de forma satisfatória, assim como pode ser observado nas respostas dos professores:

(...) P1 Acredito que sim, nas ações do dia-a-dia como também o trabalho em sala de aula, que mesmo sendo lento, se tem esse propósito, de contribuir nas ações educativas a favor de um ambiente sustentável.

(...) P2 Sim, pois sempre que possivel e necessário tento trabalhar atitudes sustentáveis, lembro problemas que os resíduos podem causar para nós e para o planeta. Levo para as aulas, documentários e textos que respaldam a necessidade de pensarmos nas consequências que nossas atitudes "não sustentáveis" podem causar a todos nós.

(...) P3 Na verdade esse é um tema que me deixa um pouco frustrada, pois apesar de ter feito minha especialização em EA, de acompanhar os fóruns da agenda 21 em meu município, de estar fazendo um curso de EA neste ano, e de direcionar a maioria dos meus trabalhos na graduação para essa área, sinto que consigo fazer muito menos do que gostaria em termos de sensibilização e conscientização. É um trabalho lento e com pouco retorno, mas não devemos desistir. O pouco que conseguimos é melhor do que nada.

Neste sentido, cabe salientar que trabalhar com as questões relacionadas ao meio ambiente, seja elas na escola, família ou na sociedade, não significam suficientes para que as mudanças de fato aconteçam. A sensibilização, as mudanças de atitudes e a sustentabilidade são objetivos que todos 
precisam buscar e desenvolver enquanto cidadãos. Mesmo que os resultados demorem a acontecer, cada pessoa precisa fazer a sua parte.

Conforme Brasil (2006):

Os professores, em seus grupos organizados, são os agentes da (re) construção curricular, sendo imprescindível a criação de espaços de planejamento coletivo, de estudos e discussões que incluam as orientações curriculares nacionais, não vistas como propostas de ensino, mas como diretrizes a serem dinamicamente significadas e desenvolvidas nos contextos de âmbitos mais locais (p.133).

No espaço de sala de aula, o professor é o mediador do conhecimento, podendo através da interação professor/aluno, trazer para o contexto de sala de aula assuntos relevantes relacionados as questões ambientais, induzindo os estudantes a refletir suas ações diárias, a rever conceitos e repensar suas atitudes, permitindo a mudança de hábito, evitando o desperdício e realizando o destino correto dos resíduos.

Todas estas ações são significativamente importantes para a minimização da problemática ambiental, entretanto somente serão possíveis a partir da conscientização dos seres humanos sobre a importância da qualidade dos ecossistemas para a manutenção de todas as formas de vida no planeta.

\section{Considerações Finais}

Os problemas ambientais relacionados com a falta de conscientização dos seres humanos sobre a problemática ambiental é considerado um dos principais intensificadores da degradação dos ecossistemas.

Neste sentido, a escola exerce um papel fundamental, formando cidadãos conscientes e comprometidos com o bem-estar do planeta. Deste modo, a temática ambiental pode ser abordada no ambiente de sala de aula, seguindo a filosofia da Educação Ambiental que se constitui uma ferramenta essencial para a formação dos seres humanos. Entretanto, os professores precisam estar preparados para atuar como agente transformador e conscientizador das questões ambientais.

Com base nos objetivos da pesquisa, foi possível compreender as dificuldades e desafios sentidos pelos professores durante a abordagem da EA no contexto de sala de aula, uma vez que por se tratar de assuntos amplos, diversificados e ricos em conceitos, sentem-se na sua maioria, despreparados para tais abordagens. O desenvolvimento das atividades vinculadas à EA durante as diversas áreas do conhecimento esbarra na fragilidade dos conceitos disciplinares, (dificuldades de abordagem de assuntos e conceitos relacionados ao meio ambiente de modo inter-relacionando com as disciplinas específicas do currículo escolar) e acabam sendo apenas desenvolvidas durante as aulas de Ciências e Biologia. A falta de metodologias práticas, inovadoras, contextualizadas e interdisciplinares, justificam as dificuldades sentidas pelos professores durante o desenvolvimento das questões ambientais. Trabalhar com a EA em sala de aula exige muita dedicação, pesquisa, persistência e força de vontade, pois os resultados na maioria das vezes demoram aparecer e os professores devem aceitar esse tempo e não desistir no caminho.

Com tudo, vale ressaltar que a abordagem de propostas inovadoras no âmbito da sala de aula, constitui-se de grande importância para formação dos estudantes, uma vez que através deste trabalho, é possível compreender os conceitos disciplinares e realizar uma ponte entre as diversas áreas curriculares, fortalecendo assim o processo de ensino aprendizagem.

A Educação Ambiental é um processo longo, complexo e de permanente construção e reconstrução, que exige a participação e o envolvimento de toda a sociedade. Para isso, precisamos nos comprometer com o meio ambiente, minimizando os prejuízos e evitando a degradação dos ecossistemas como um todo. 


\section{Referências}

BOFF, Eva Teresinha de Oliveira; GOETTEMS, Pauline Brendler; DEL PINO, José Cláudio. Ambiente e Vida - O Ser Humano Nesse Contexto: Uma Estratégia de Ensino Transformadora do Currículo Escolar. Rev. Eletrônica: Mestrado em Educ. Ambiental. ISSN 1517-1256, v. 26, janeiro a junho de 2011.

BOFF, Eva Teresinha de Oliveira; FRISON, Marli; DEL PINO, José Claudio. Significação de Conteúdos Escolares no Contexto da Educação Ambiental. VII Simpósio Internacional de Qualidade Ambiental 2010.

BORGES, Leonardo Estrela. Direito Ambiental Internacional e Terrorismo: Os Impactos no Meio Ambiente. Boletim Científico Escola Superior do Ministério Público da União, (2003).

http://boletimcientifico.escola.mpu.mp.br/. Acesso em: 10 nov. 2014.

BRASIL. Lei no 9.394, de 20 de dezembro de 1996. Diretrizes e Bases da Educação Nacional. Brasília, DF, 1996. P. 1-31. Disponível em: http://portal.mec.gov.br/seed/arquivos/pdf/tvescola/leis/lein9394.pdf Acesso em: 12 nov.2014.

BRASIL, Lei no 11.520, de 03 de agosto de 2000. Código Estadual do Meio Ambiente do Estado do Rio Grande do Sul. Porto Alegre/ RS. Disponível em: http://www.al.rs.gov.br/legiscomp/arquivo.asp?idNorma=11Etipo=pdf Acesso em: 11 nov.2014.

BRASIL. Lei no 6.938, de 31 agosto de 1981. Politica Nacional de Meio Ambiente. Disponível em: http://www.planalto.gov.br/ccivil 03/leis/l6938.htm Acesso em: 12.nov.2014.

BRASIL. Ministério da Educação (MEC), Secretaria de Educação Básica (SEB), Departamento de Políticas de Ensino Médio. Orientações Curriculares do Ensino Médio. Brasília: MEC/SEB, 2004.

BRASIL. MEC. UNESCO. O que fazem as escolas que dizem que fazem educação ambiental. (2007). Disponível em: http://portal.mec.gov.br/dmdocuments/publicacao5.pdf Acesso em: 07 set.2014.

BRASIL. Secretaria de Educação Fundamental. Parâmetros Curriculares Nacionais: Introdução aos Parâmetros Curriculares Nacionais/Secretaria de Educação Fundamental. - Brasília : MEC/SEF, 1997. 126p.

BRASIL. Parâmetros Curriculares Nacionais - Ciências Naturais. Brasília, 1999

BRASIL, Coleção Educação para todos. Ministério da Educação (MEC), 2007.

BRASIL. Não vamos Desistir do Brasil. Ministério da Educação (MEC), 2007.

Disponível em: http://portal.mec.gov.br/dmdocuments/publicacao3.pdf Acesso em: 12 nov.2014.

CACHAPUZ, A. et al. (Orgs.). A necessária renovação do ensino das ciências. São Paulo: Cortez, 2005.

DEMO, Pedro. Conhecer e aprender: sabedoria dos limites e desafios. Porto Alegre: Artmed, 2000.

FADINI, P.S.; FADINI, A. A. B. (2001). Lixo: desafios e compromissos. Cadernos Temáticos de Química Nova na Escola. Edição especial - Maio, SP. 
FAGUNDES, S. M. K. Experimentação nas Aulas de Ciências: Um Meio para a Formação da Autonomia? In: GALIAZZI, M. C. et al. Construção Curricular em Rede na Educação em Ciências: Uma Aposta de Pesquisa na Sala de Aula. Ijuí: Unijui, 2007.

FAZENDA, Ivani. Práticas interdisciplinares na escola. São Paulo: Cortez, 2001.

FREIRE, Paulo. Pedagogia da Autonomia: saberes necessários à prática educativa. São Paulo: Paz e Terra, 1996. (Coleção Leitura)

GALIAZZI, Maria do Carmo; MORAES, Roque. Educação pela pesquisa como modo, tempo e espaço de qualificação da formação de professores de ciências. Ciência \& Educação, Bauru, v. 8, n. 2, p. 237252, 2002. Disponível em: http://wwww.scielo.br/pdf/ciedu/v8n2/08.pdf. Acesso em: 10 dez.2014.

MALDANER, Otavio Aloisio. A formação inicial e continuada de professores de química professores/pesquisador. Ijuí: Ed. Unijuí, 2000.

MANZINI, E. J. A entrevista na pesquisa social. Didática, São Paulo, v. 26/27, p. 149-158, 1990/1991.

MOURA, L. A. A. de. (2004). Qualidade e gestão ambiental. 4 ed. São Paulo: Juarez de Oliveira.

MORADILLO, Edilson Fortuna. OKI, Maria da Conceição Marinho. Educação ambiental na universidade: construindo possibilidades. Quím. Nova 2004, vol.27, n.2, pp. 332-336. ISSN 0100-4042.

MORAES, Roque; GALIAZZI, Maria do Carmo. Análise Textual Discursiva. Ijuí: UNIJUÍ, 2007.

PRADO, Ricardo. Um “trem-bão" chamado interdisciplinaridade. Edição n 122 , Revista Nova Escola, de maio de 1999.

ROA, K. R.V.; SILVA, G.; NEVES, L. B. U.; WARIGODA, M. S.; (2009) Curso de Formação Continuada de Professores. Pilhas e Baterias: Usos e Descartes X Impactos Ambientais. Disponível em:

http://www.cienciamao.usp.br/dados/aas/ indefinidopilhasebateria.arquivo.pdf. Acesso em: 08 out. 2014.

RIO GRANDE DO SUL. Secretaria Estadual do Meio Ambiente. Código Estadual de Meio Ambiente. Lei Estadual $N^{\circ} \quad \mathbf{1 1 . 5 2 0 / 2 0 0 0} . \quad$ Porto Alegre: $2000 . \quad$ Fonte: http://www.al.rs.gov.br/legiscomp/arquivo.asp?idNorma=11\&tipo=pdf Acesso em: 15 nov.2014.

SILVA, R. N.; Chaves, P. M.; Ghiggi, G. IX, ANPED Sul: Seminário de Pesquisa em Educação da Região Sul, 2012. Formação Permanente: A Pesquisa Como Princípio Articulador da Prática Docente. Disponível em: http://www.ucs.br/etc/conferencias/index.php/anpedsul/9anpedsul/paper/viewFile/2676/578 Acesso em: 15 nov.12.

SILVA, et al, 2009. A Importância da Utilização de Atividades Práticas Como Estratégia Didática para o Ensino de Ciências.

Disponível em: http://www.eventosufrpe.com.br/jepex2009/cd/resumos/r0610-2.pdf Acesso em: 15 nov.2014.

SOUZA, M. L.; GALIAZZI, M. do C. Educação Ambiental em Projetos de Aprendizagem: as lidas de um grupo de professoras na tecitura de uma rede de coletivos. In: GALIAZZI Maria do Carmo et al. Construção curricular em rede na educação em ciências: uma aposta de pesquisa na sala de aula. Ijuí: 
Editora Unijuí, 2007, p. 297-316.

SOUZA, R. S. de. Entendendo a questão ambiental. Santa Cruz do Sul, Ed. EDUNISC, p.46- 87, 2000.

TOMASI, D. B. As vertentes da educação ambiental. IN: MARQUES, Mario Osório (org.). Educação, Saberes Distintos, Entendimento Compartilhado. Ijuí, Ed. Unijuí, 2000 (pp. 184-199).

VASCONCELLOS, Celso dos Santos, 1956 - Avaliação da Aprendizagem: Práticas de Mudanças por um Praxis Transformadora. São Paulo: Libertad, 1998- (Coleção Cadernos pedagógicos do Libertad; v 6). 
APÊNDICE - QUESTIONÁRIO DESENVOLVIDO COM OS PROFESSORES DE CIÊNCIAS, BIOLOGIA, QUÍMICA E FÍSICA.

1. Qual a sua compreensão sobre EA na escola?

2. Quais dificuldades sentidas para a abordagem das questões ambientais durante as suas aulas?

3. O que você pode fazer para auxiliar na sensibilização dos estudantes para a preservação do meio ambiente?

4. Como você vê a abordagem da interdisciplinaridade durante as suas aulas?

5. Você se sente amparada pela escola e preparada para a realização do trabalho interdisciplinar?

6. qual a sua compreensão sobre a sustentabilidade?

7. No contexto de sala de aula, como você percebe o interesse dos estudantes pelos assuntos relacionados ao meio ambiente?

8. De quem é a responsabilidade da produção e gerenciamento dos resíduos?

9. Qual tipo de "lixo" você considera ser mais prejudicial à saúde?

10. Quais os problemas ambientais causados pelo mau gerenciamento do "lixo"?

11. Qual a necessidade sentida para a realização de atividades relacionadas com o meio ambiente?

12. Você acredita estar fazendo a sua parte para reduzir os problemas ambientais a médio e longo prazo? 